\title{
Effect of Methyl Group Substitution on the Kinetics of Vinyl Radical + O-2 Reaction
}

\section{Joshi, Satya P.}

2019-12-12

Joshi , S P , Pekkanen , T T , Timonen , R S \& Eskola , A J 2019 , ' Effect of Methyl Group Substitution on the Kinetics of Vinyl Radical + O-2 Reaction ' , Journal of Physical Chemistry A , vol. 123 , no. 49 , pp. 10514-10519 . https://doi.org/10.1021/acs.jpca.9b08028

http://hdl.handle.net/10138/321155

https://doi.org/10.1021/acs.jpca.9b08028

unspecified

acceptedVersion

Downloaded from Helda, University of Helsinki institutional repository.

This is an electronic reprint of the original article.

This reprint may differ from the original in pagination and typographic detail.

Please cite the original version. 


\title{
Effect of Methyl Group Substitution on the Kinetics of Vinyl Radical $+\mathrm{O}_{2}$ Reaction
}

\author{
Satya P. Joshi, Timo T. Pekkanen, Raimo S. Timonen, Arkke J. Eskola* \\ Department of Chemistry, University of Helsinki, P.O. Box 55(A.I. Virtasen aukio 1), FI-00014, \\ Helsinki, Finland \\ *corresponding author: arkke.eskola@helsinki.fi
}

\section{ORCID}

Satya P. Joshi:

Timo T. Pekkanen:

Raimo S. Timonen:

Arkke J. Eskola: 0000-0002-2249-2726

\begin{abstract}
The kinetics of $\left(\mathrm{CH}_{3}\right)_{2} \mathrm{CCH}+\mathrm{O}_{2}(1)$ and $\left(\mathrm{CH}_{3}\right)_{2} \mathrm{CCCH}_{3}+\mathrm{O}_{2}(2)$ reactions have been measured as a function of temperature $(223-600 \mathrm{~K})$ at low pressures $(0.4-2$ Torr $)$ using a tubular laminar flow reactor coupled to a photoionization mass spectrometer (PIMS). These reactions are important for accurate modeling of unsaturated hydrocarbon combustion. Photolysis of a brominated precursor by a pulsed excimer laser radiation at $248 \mathrm{~nm}$ wavelength along the flow reactor axis was used for the production of radicals. The measured bimolecular rate coefficient of reaction (1) shows a negative temperature dependence over the temperature range $223-384 \mathrm{~K}$ and becomes temperature independent at higher temperatures. The bimolecular rate coefficient of reaction (2) exhibits a
\end{abstract}


negative temperature dependence throughout the experimental temperature range. The bimolecular rate coefficients of reactions (1) and (2) are expected to be at the high-pressure-limit under the current experimental conditions and the following values are obtained at $298 \mathrm{~K}: k_{1}(298 \mathrm{~K})=(4.5 \pm 0.5) \times 10^{-}$ ${ }^{12} \mathrm{~cm}^{3} \mathrm{~s}^{-1}$ and $k_{2}(298 \mathrm{~K})=(8.9 \pm 1.0) \times 10^{-12} \mathrm{~cm}^{3} \mathrm{~s}^{-1}$. The observed products for reactions (1) and (2) were $\mathrm{CH}_{3} \mathrm{COCH}_{3}$ and $\mathrm{CH}_{3}+\mathrm{CH}_{3} \mathrm{COCH}_{3}$, respectively. Substituting both $\beta$-hydrogens in vinyl radical $\left(\mathrm{CH}_{2} \mathrm{CH}\right)$ with methyl groups decreases the rate coefficient of $\mathrm{CH}_{2} \mathrm{CH}+\mathrm{O}_{2}$ reaction by about $50 \%$. However, the rate coefficient of the triply substituted $\left(\mathrm{CH}_{3}\right)_{2} \mathrm{CCCH}_{3}$ radical reaction with $\mathrm{O}_{2}$ is almost identical to the $\mathrm{CH}_{2} \mathrm{CH}+\mathrm{O}_{2}$ rate coefficient under the covered temperature range.

\section{Introduction}

Unsaturated hydrocarbons, either as fuel constituents or combustion intermediates, play an important role in determining combustion properties of conventional fuels, such as octane number, ignition delay time, flame speed, soot formation propensity etc.. Their role can be expected to become even more important with the increasing use of bio-fuels in the transportation sector. ${ }^{1-4}$ Resonancestabilized allylic radicals (R) are formed in high yields in abstraction reactions of weakly-bonded allylic hydrogen(s) from an unsaturated hydrocarbon and are less reactive towards $\mathrm{O}_{2}$ compared to alkyl radicals. This is due to the combined effect of shallow $\mathrm{RO}_{2}$ potential energy wells (e.g. $\sim 18$ $\mathrm{kcal} / \mathrm{mol}$ for allyl ${ }^{5}$ compared to $\sim 33 \mathrm{kcal} / \mathrm{mol}$ for ethyl ${ }^{6}$ radical) and high barrier(s) for further $\mathrm{RO}_{2}$ isomerization, ${ }^{5,7}$ which means that the dominant loss pathway for the $\mathrm{RO}_{2}$ adduct is dissociation back to reactants. Under these conditions, $\mathrm{R}+$ fuel and $\mathrm{R}+\mathrm{R}$ reactions may become important and lead to incomplete combustion and soot formation. Vinyl-type radicals, on the other hand, are produced in lower yields than allyl-type radicals in hydrogen atom abstraction reactions from unsaturated hydrocarbons fuels because of stronger vinylic $\mathrm{C}-\mathrm{H}$ bond strengths compared to the weaker allylic C-H bonds. However, vinyl-type radicals $(\mathrm{R})$ react significantly faster with $\mathrm{O}_{2}$ than allyl-type radicals under wide range of conditions, mainly due to significantly deeper $\mathrm{RO}_{2}$ potential energy wells $(\sim 40$ $\mathrm{kcal} / \mathrm{mol}$ for vinyl ${ }^{8,9}$ compared to $\sim 18 \mathrm{kcal} / \mathrm{mol}$ for allyl ${ }^{5}$ radicals) and low barriers for further $\mathrm{RO}_{2}$ 
isomerization to bimolecular products. ${ }^{5,8,9}$ Due to the high reactivity of vinyl-type radicals with $\mathrm{O}_{2}$, especially in comparison to allyl-type radicals, rigorous combustion models of unsaturated hydrocarbon fuels need accurate information on the kinetics and reactivity of vinyl-type radicals with $\mathrm{O}_{2}{ }^{10-12}$ Furthermore, sensitivity analyses performed on oxidation of unsaturated fuels typically show that the production of vinyl-type radicals increases fuel reactivity. ${ }^{11}$ Hence, it is important to understand the oxidation kinetics of vinyl-type radicals to accurately model the combustion of unsaturated hydrocarbons.

Majority of the previous studies of vinyl-type radicals with molecular oxygen have been confined to the kinetics of reaction $\mathrm{CH}_{2} \mathrm{CH}+\mathrm{O}_{2} \cdot{ }^{13-20}$ However, in our recent work we studied the kinetics of methyl-vinyl radicals with molecular oxygen and observed that substituting the $\alpha$-hydrogen of vinyl radical with a methyl group increased reactivity towards $\mathrm{O}_{2}$, whereas substituting a $\beta$-hydrogen with a methyl group decreased reactivity towards $\mathrm{O}_{2} \cdot{ }^{21}$ In this work, we have further investigated the reactivity trends by measuring the kinetics of 2,2-dimethylvinyl and 1,2,2-trimethylvinyl radicals with molecular oxygen as function of temperature.

$$
\begin{aligned}
& \left(\mathrm{CH}_{3}\right)_{2} \mathrm{CCH}+\mathrm{O}_{2} \rightarrow \text { Products } \\
& \left(\mathrm{CH}_{3}\right)_{2} \mathrm{CCCH}_{3}+\mathrm{O}_{2} \rightarrow \text { Products }
\end{aligned}
$$

Under combustion conditions 2,2-dimethylvinyl and 1,2,2-trimethylvinyl radicals can be formed, for example, in hydrogen atom abstraction reactions from isobutene and 2-methyl-2-butene, respectively. Reaction products were also sought for reactions (1) and (2). Reaction (1) is used to probe the effect of methyl group substitution to both the available $\beta$ positions of the vinyl radical and reaction (2) is used to investigate the comparative net effect of methyl group substitution to all the available $\alpha$ and $\beta$ positions. Scheme 1 shows the vinyl-type radicals under study in this work and in our previous work. We are not aware of any previous experimental kinetic study of reactions (1) and (2). To our best knowledge, current work is also the first study of $\left(\mathrm{CH}_{3}\right)_{2} \mathrm{CCH}$ and $\left(\mathrm{CH}_{3}\right)_{2} \mathrm{CCCH}_{3}$ radicals. 


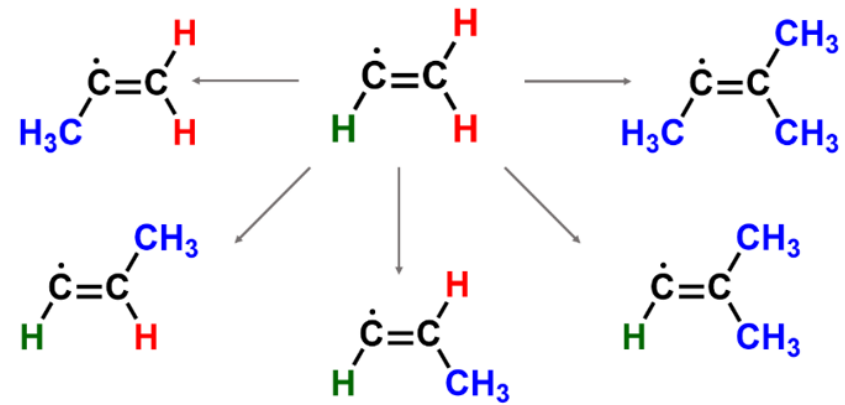

Scheme 1: The vinyl-type radicals produced when $\alpha$ (green) and $\beta$ (red) hydrogens of vinyl radical are substituted with methyl groups. The kinetics of $\mathrm{CH}_{3} \mathrm{CCH}_{2}+\mathrm{O}_{2}$ and cis/trans $-\mathrm{CH}_{3} \mathrm{CHCH}+\mathrm{O}_{2}$ reactions have been measured previously. ${ }^{21}$

Recent high-level calculations show that the addition of molecular oxygen to vinyl and methyl-vinyl radicals is a barrierless process, ${ }^{8,9}$ in good agreement with results of direct kinetic measurements of these reactions, where negative temperature dependency is observed at low temperatures. ${ }^{20,21}$ Consequently, reactions (1) and (2) are almost certainly barrierless reactions. Barrierless hydrocarbon radical reactions with molecular oxygen are ubiquitous in any combustion environment, but their accurate theoretical kinetic calculations are very demanding and the cost of such calculations increases steeply with system size (number of "heavy atoms"). For example, Goldsmith et al. ${ }^{8}$ calculated the energetics of the vinyl $+\mathrm{O}_{2}$ system with the highly accurate ANL0 compound method, but this method is already too expensive for the slightly larger methyl-vinyl $+\mathrm{O}_{2}$ system. ${ }^{9}$ Accurate rate calculations of barrierless reactions also require detailed information about the attractive surface between reactants. These calculations are quite challenging even for relatively small systems and become increasingly complicated as system size increases. For this reason, our direct kinetic experiments of reactions (1) and (2) also serve as an important reference for future calculations.

\section{Experimental Section}

A brominated precursor was photolyzed using $248 \mathrm{~nm}$ radiation from an excimer laser (ASX-750) operating at $5 \mathrm{~Hz}$ to produce the radical of interest $(\mathrm{R})$, which then reacted with a known concentration 
of oxygen $\left(\mathrm{O}_{2}\right.$, Aga, $99.998 \%$ purity) present in a homogeneous gas-mixture consisting mainly of helium (He, Messer-Griesheim, 99.9996\% purity) and flowing through the laminar flow reactor. Kinetics of the $\mathrm{R}+\mathrm{O}_{2}$ reactions were measured by detecting a temporal radical decay profile using a photoionization mass spectrometer (PIMS) coupled with the flow reactor. A detailed description of the PIMS apparatus has been explained previously, ${ }^{20}$ and only the necessary details regarding the current measurements will be explained here.

$\left(\mathrm{CH}_{3}\right)_{2} \mathrm{CCH}$ and $\left(\mathrm{CH}_{3}\right)_{2} \mathrm{CCCH}_{3}$ radicals were produced from 1-bromo-2-methyl-1-propene and 2bromo-3-methyl-2-butene precursors, respectively.

$$
\begin{aligned}
\left(\mathrm{CH}_{3}\right)_{2} \mathrm{CCHBr}+h v(248 \mathrm{~nm}) & \rightarrow\left(\mathrm{CH}_{3}\right)_{2} \mathrm{CCH}+\mathrm{Br} \\
& \rightarrow \text { Other products } \\
\left(\mathrm{CH}_{3}\right)_{2} \mathrm{CC}(\mathrm{Br}) \mathrm{CH}_{3}+h v(248 \mathrm{~nm}) & \rightarrow\left(\mathrm{CH}_{3}\right)_{2} \mathrm{CCH}_{3}+\mathrm{Br} \\
& \rightarrow \text { Other products }
\end{aligned}
$$

Experiments were conducted under the temperature and pressure range of $223-600 \mathrm{~K}$ and $0.4-2$ Torr, respectively. Different reactor/coating combinations were used to minimize radical decay rate on reactor wall at different temperatures. A stainless steel reactor $(i . d .=1.7 \mathrm{~cm}$ ) with halocarbon wax coating $^{22}$ was used up to $363 \mathrm{~K}$. At higher temperatures a quartz reactor (i.d. $=1.7 \mathrm{~cm}$ ) with boric acid coating $^{23}$ or a Pyrex reactor $($ i.d. $=1.7 \mathrm{~cm})$ with Polydimethylsiloxane $($ PDMS) coating was employed. ${ }^{22}$ Pyrex and quartz flow reactors were resistively heated and coupled with a PID-controlled heating system, producing temperature uniformity of about $\pm 3 \mathrm{~K}$ over current experimental conditions.

Photoionization of radical R in the kinetic experiments of reactions (1) and (2) was carried out using a Cl-lamp $\left(\mathrm{Cl}_{2}\right.$-helium mixture $)$ with a $\mathrm{BaF}_{2}$ window $(8.9 \mathrm{eV})$ to produce $\left(\mathrm{CH}_{3}\right)_{2} \mathrm{CCH}^{+}(\mathrm{m} / z=43)$ and $\left(\mathrm{CH}_{3}\right)_{2} \mathrm{CCCH}_{3}{ }^{+}(\mathrm{m} / \mathrm{z}=69)$ ions. The products of reactions (1) and (2) were ionized using a $\mathrm{H}_{2}$-lamp 
with $\mathrm{MgF}_{2}$ window $(10.2 \mathrm{eV})$. Ions produced were selected according to their $\mathrm{m} / \mathrm{z}$ ratio using a quadrupole mass-spectrometer and subsequent detection was carried-out using an off-axis electron multiplier. The ion signal was then amplified and discriminated before being sent to a PC for further analysis.

In addition to the reaction of primary interest, $\mathrm{R}+\mathrm{O}_{2} \rightarrow$ Products, other processes which contribute to the radical decay rate in the reactor are heterogeneous wall decay $k_{\text {wall }}$ and potentially also radical - radical and radical - precursor reactions to some small extent.

$$
\begin{aligned}
& \mathrm{R} \stackrel{k_{\text {wall }}}{\longrightarrow} \text { Heterogeneous loss } \\
& \mathrm{R}+\mathrm{R} \rightarrow \text { Products }
\end{aligned}
$$

The measurements were always started by first measuring $k_{\text {wall, }}$ the $\mathrm{R}$ decay rate without added $\mathrm{O}_{2}$. Any contribution due to reaction (B) was minimized by adjusting (reducing) the laser power and/or amount of precursor until the initial radical decay did not anymore depend on these parameters. Initial $\mathrm{R}$ concentrations were typically below $2 \times 10^{11} \mathrm{~cm}^{-3}$. Once these conditions were met, radical R decay signals with different added $\left[\mathrm{O}_{2}\right]$ were typically collected from $10 \mathrm{~ms}$ before to $40 \mathrm{~ms}$ after each laser pulse using a multichannel scaler. Experiments were repeated 3000 - 9000 times while laser repetition rate was maintained at $5 \mathrm{~Hz}$. Each radical decay profile was then fitted using an exponential function, $\left[R_{t}\right]=A+\left[R_{0}\right] \times \exp \left(-k^{\prime} t\right)$. Here $A$ is the signal background, $k^{\prime}$ is the pseudo-first-order decay rate coefficient, and $\left[R_{t}\right]$ is signal value that is proportional to temporal radical concentration.

Measurements were performed under pseudo-first-order conditions (i.e. $[\mathrm{R}] \ll\left[\mathrm{O}_{2}\right]$ ) and the $[\mathrm{R}] /\left[\mathrm{O}_{2}\right]$ ratio was estimated to be always below 0.04 . By plotting the obtained pseudo-first-order decay rate coefficients $k^{\prime}$ as a linear function of molecular oxygen concentration $\left[\mathrm{O}_{2}\right]$, the bimolecular rate coefficient of $\mathrm{R}+\mathrm{O}_{2} \rightarrow$ Products reaction, $k\left(\mathrm{R}+\mathrm{O}_{2}\right)$, was obtained from the slope of the equation $k^{\prime}=k_{\text {wall }}+k\left(\mathrm{R}+\mathrm{O}_{2}\right) \times\left[\mathrm{O}_{2}\right]$ fitted to the data. As an additional check of the obtained data consistency, the measured $k_{\text {wall }}$ were compared with the $y$-axis intercepts of the bimolecular plots. Freeze-pump- 
thaw technique was used to remove any air from the 1-bromo-2-methyl-1-propene (Sigma-Aldrich, $>98 \%$ ) and 2-bromo-3-methyl-2-butene (Sigma-Aldrich, $>96 \%$ ) precursor samples before use.

\section{Results and Discussion}

Representative bimolecular plots for reaction (1) $\left(\mathrm{CH}_{3}\right)_{2} \mathrm{CCH}+\mathrm{O}_{2} \rightarrow$ Products and reaction (2) $\left(\mathrm{CH}_{3}\right)_{2} \mathrm{CCCH}_{3}+\mathrm{O}_{2} \rightarrow$ Products are shown in the Figure 1. Also shown are examples of radical ion decay and product ion formation signals. Products formed in reactions (1) and (2) can be classified as either closed-shell (i.e. $\mathrm{CH}_{3} \mathrm{COCH}_{3}$ ) or open-shell (i.e. $\mathrm{CH}_{3}$ ) products. Non-linear least squares fits

of $\quad \mathrm{I}_{t}\left(\mathrm{P}^{+}\right)=B+\mathrm{I}_{0}\left(\mathrm{P}^{+}\right)\left(1-\exp \left(-k^{\prime} t\right)\right) \quad$ and $\quad \mathrm{I}_{t}\left(\mathrm{P}^{+}\right)=B+\mathrm{I}_{0}\left(\mathrm{P}^{+}\right)\left(\frac{k^{\prime}}{k^{\prime}-k_{p}^{\prime}}\right)\left(\exp \left(-k_{p}^{\prime} t\right)-\right.$ $\left.\exp \left(-k^{\prime} t\right)\right)$ expressions to the data were performed for closed-shell and open-shell products formation signals as shown in Figure 1 insets. Here parameter $B$ is the background signal, $\mathrm{I}_{0}\left(\mathrm{P}^{+}\right)$is the signal value at $t \rightarrow \infty$, corresponding to channel yield $\times[\mathrm{R}]_{0}, k^{\prime}$ is the pseudo-first-order decay for reactions (1) or (2) and $k_{p}^{\prime}$ (treated as an individual fitting parameter) is the pseudo-first-order rate coefficient associated with the reaction of open-shell species $\left(\right.$ i.e. $\left.\mathrm{CH}_{3}\right)$ with $\mathrm{O}_{2}$. The value of $k^{\prime}$ remains unaltered within $2 \sigma$-uncertainty if we treat it as an individual fitting parameter, showing observed product originates from the reaction of interest and that there are no secondary sources of the product. 

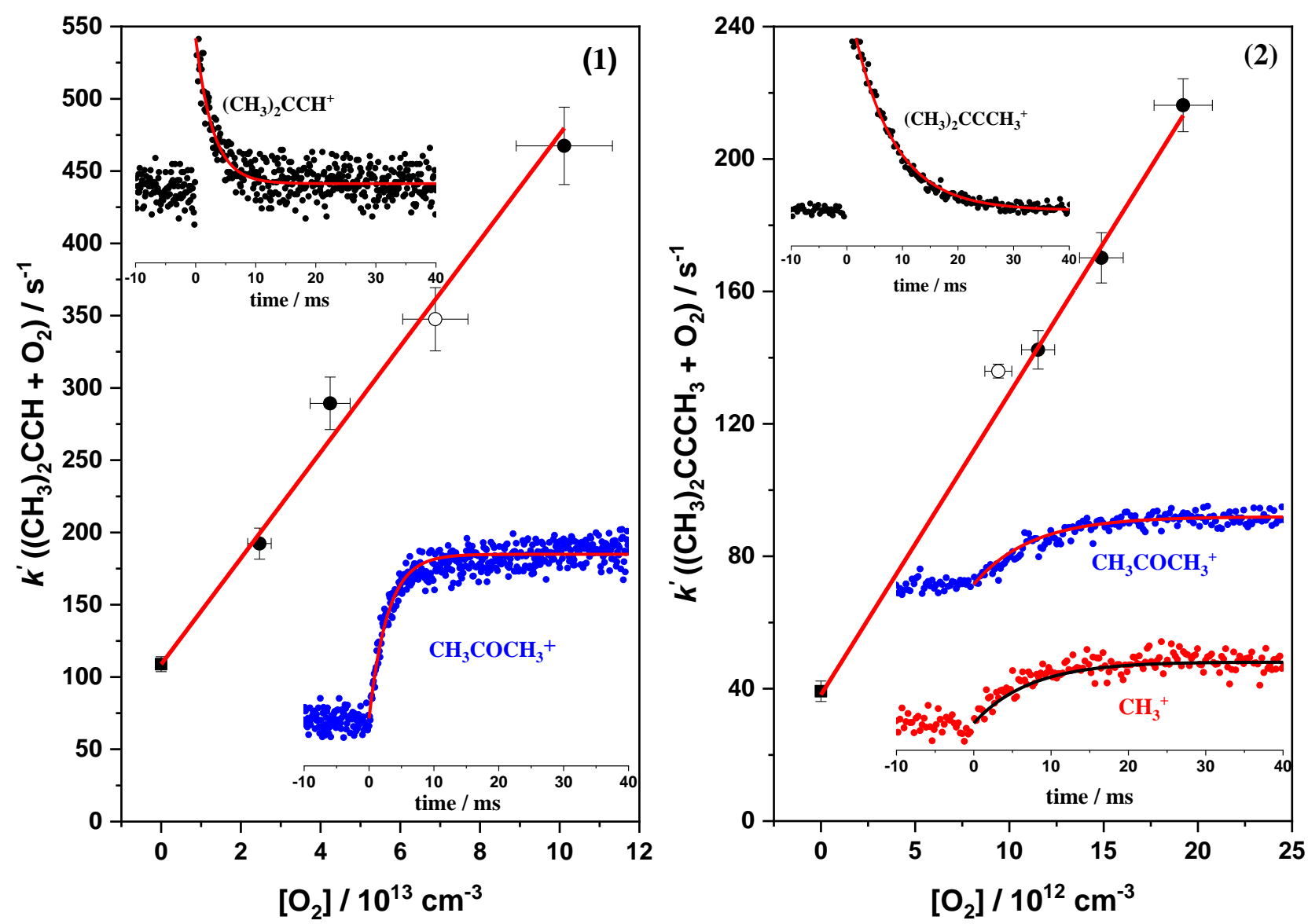

Figure 1. The left and right hand side represent the bimolecular plots for reaction (1) $\left(\mathrm{CH}_{3}\right)_{2} \mathrm{CCH}+$ $\mathrm{O}_{2}(T=344 \mathrm{~K}, p=0.95$ Torr $)$ and (2) $\left(\mathrm{CH}_{3}\right)_{2} \mathrm{CCCH}_{3}+\mathrm{O}_{2}(T=298 \mathrm{~K}, p=1.60$ Torr $)$, respectively. Also shown are typical radical ion decay profile (top left corner of each plot) and product formation ion signal profiles (bottom right corner of each plot) measured under conditions shown as unfilled circles in plots (1) and (2), respectively. Uncertainties shown are $1 \sigma$.

The observed products were $\mathrm{CH}_{3} \mathrm{COCH}_{3}$ for reaction (1) and $\mathrm{CH}_{3}$ and $\mathrm{CH}_{3} \mathrm{COCH}_{3}$ for reaction (2). Assuming reactions (1) and (2) have a similar mechanism to the $\mathrm{C}_{2} \mathrm{H}_{3}+\mathrm{O}_{2} \rightarrow \mathrm{HCO}+\mathrm{H}_{2} \mathrm{CO}$ reaction, one would expect to observe $\mathrm{HCO}+\mathrm{CH}_{3} \mathrm{COCH}_{3}$ and $\mathrm{CH}_{3} \mathrm{CO}+\mathrm{CH}_{3} \mathrm{COCH}_{3}$ products for reactions (1) and (2), respectively. A signal was observed at nominal $\mathrm{m} / \mathrm{z}=29$ for reaction (1). Unfortunately, a significant portion of this signal originated, most likely, from dissociative ionization of $\left(\mathrm{CH}_{3}\right)_{2} \mathrm{CCH}$ radical to $\mathrm{C}_{2} \mathrm{H}_{5}^{+}$cation $\left(\mathrm{m} / z\left(\mathrm{C}_{2} \mathrm{H}_{5}\right)=29.03913\right)$ when a $\mathrm{H}_{2}$ lamp with an $\mathrm{MgF}_{2}$ window was employed. This prevented us to unambiguously detect $\mathrm{HCO}(\mathrm{m} / z(\mathrm{HCO})=29.00275)$ as a product of 
reaction (1). Also, no $\mathrm{CH}_{3} \mathrm{CO}$ was observed for reaction (2). The most likely explanation for the absence of $\mathrm{CH}_{3} \mathrm{CO}$ and the presence of $\mathrm{CH}_{3}$ as product of reaction (2) with the correct time-behavior is that $\mathrm{CH}_{3} \mathrm{CO}$ is formed with enough excess energy to undergo chemically-activated unimolecular decomposition to $\mathrm{CH}_{3}$ and $\mathrm{CO}$ before stabilization under current low-pressure conditions. This explanation is supported by the recent calculations of Chen and Goldsmith ${ }^{9}$ on chemically similar system, $\mathrm{CH}_{3} \mathrm{CCH}_{2}+\mathrm{O}_{2}$ reaction. They calculated $\Delta_{\mathrm{r}} \mathrm{H}=-366 \mathrm{~kJ} / \mathrm{mol}$ for $\mathrm{CH}_{3} \mathrm{CCH}_{2}+\mathrm{O}_{2} \rightarrow \mathrm{CH}_{3} \mathrm{CO}$ $+\mathrm{H}_{2} \mathrm{CO}$ reaction channel, clearly indicating both $\mathrm{CH}_{3} \mathrm{CO}$ radical and $\mathrm{H}_{2} \mathrm{CO}$ are formed in highly vibrationally excited and acetyl radical undergo rapid unimolecular decomposition $\mathrm{CH}_{3} \mathrm{CO} \rightarrow \mathrm{CH}_{3}+$ $\mathrm{CO}\left(\Delta_{\mathrm{r}} \mathrm{H}\left(\mathrm{CH}_{3} \mathrm{CO} \rightarrow \mathrm{CH}_{3}+\mathrm{CO}\right)=45.1 \mathrm{~kJ} / \mathrm{mol}\right)^{24}$ and produce methyl radical. Similarly, the $\mathrm{C}_{2} \mathrm{H}_{3}+$ $\mathrm{O}_{2} \rightarrow \mathrm{HCO}+\mathrm{H}_{2} \mathrm{CO}$ reaction is very exothermic $\left(\Delta_{\mathrm{r}} H=-365 \mathrm{~kJ} / \mathrm{mol}\right)$ and a highly vibrationally excited $\mathrm{HCO}$ radical is formed, which mostly dissociates to $\mathrm{H}+\mathrm{CO}$ species $\left(\Delta_{\mathrm{r}} H(\mathrm{HCO} \rightarrow \mathrm{H}+\mathrm{CO})\right.$ $=61.5 \mathrm{~kJ} / \mathrm{mol}$ ) on a time scale faster than collisional stabilization. ${ }^{8}$

The main channel of reactions (1) and (2) is probably the same as for vinyl $+\mathrm{O}_{2}$ and methyl-vinyl + $\mathrm{O}_{2}$ reactions, which have been studied previously both experimentally ${ }^{16,20,21,25}$ and theoretically ${ }^{8,9}$, ${ }^{26}$. Measured vinyl and substituted vinyl radical reactions with molecular oxygen are fast and the observed products always follow the channel (C1) with any combination of hydrogen atom and methyl-group substitution at $\mathrm{R}_{1}, \mathrm{R}_{2}$, and $\mathrm{R}_{3}$. Note that $\mathrm{R}_{3}-\mathrm{CO}$ may further decompose to $\mathrm{R}_{3}$ and $\mathrm{CO}$ as discussed above.

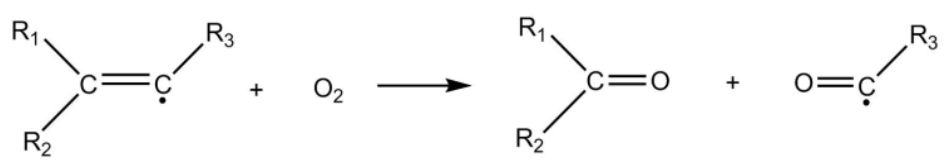

According to the theoretical studies of vinyl $+\mathrm{O}_{2}$ and methyl-vinyl $+\mathrm{O}_{2}$ reactions, the thermodynamically most favorable channel proceeds from the formed peroxyl radical to the formation of a 3-membered ring $\begin{aligned} & i \\ & 0\end{aligned}<<<$ followed by a ring opening isomerization reaction to the products shown in channel (C1). The corresponding products are observed in this study. Chen and Goldsmith ${ }^{9}$ observed in their theoretical study of $\mathrm{CH}_{3} \mathrm{CCH}_{2}+\mathrm{O}_{2}$ and trans $-\mathrm{CH}_{3} \mathrm{CHCH}+\mathrm{O}_{2}$ reactions that the channel leading to chain-branching products $\mathrm{CH}_{3} \mathrm{C}(=\mathrm{O}) \mathrm{CH}_{2}+\mathrm{O}$ and $\mathrm{CH}_{3} \mathrm{CHCHO}+\mathrm{O}$, 
respectively, is much less important than in vinyl $+\mathrm{O}_{2}$ reaction. Reason for this important observation is that methyl substitution on either carbon of vinyl radical reduces the energy of the rate-determining transition-state of channel $(\mathrm{C} 1)$, while increasing the energy of the rate-determining transition-state of channel leading to chain-branching products. The net effect is that channel (C1) becomes much more favorable and the chain-branching channel is not any more competitive. We expect the situation for reactions (1) and (2) to be similar to methyl-vinyl $+\mathrm{O}_{2}$ reactions and main reaction channel is (C1). Other products are also formed in these highly exothermic reactions but at much lower yield, especially under low-pressure conditions of the current and previous experimental studies.

The bimolecular rate coefficients measurements of reactions (1) and (2), as well as corresponding experimental conditions employed, are reported in the Table 1. The overall uncertainty in the measured bimolecular rate coefficient reported in Table 1 is about $\pm 20 \%$, most of which originates from statistical errors in the fitting procedure and uncertainties in the employed oxygen concentrations.

Table 1. The experimental conditions and results of the bimolecular rate coefficient measurements for reactions (1) and (2). The reported overall uncertainty for the measured bimolecular rate coefficient is $1 \sigma$-fitting uncertainty + estimate of other uncertainties. Reported uncertainties for $k_{\text {wall }}$ are $1 \sigma$.

\begin{tabular}{|c|c|c|c|c|c|c|c|c|}
\hline $\begin{array}{l}T^{\mathrm{a}} \\
(\mathbf{K})\end{array}$ & $\begin{array}{l}p_{\mathrm{He}} \\
\text { (Torr) }\end{array}$ & $\begin{array}{l}{[\mathrm{He}]} \\
\left(\mathrm{cm}^{-3}\right) \\
10^{16}\end{array}$ & $\begin{array}{l}\mathrm{Pr}] \\
\left(\mathrm{cm}^{-3}\right) \\
10^{12}\end{array}$ & $\begin{array}{l}{\left[\mathrm{O}_{2}\right]} \\
\left(\mathrm{cm}^{-3}\right) \\
10^{12}\end{array}$ & $\begin{array}{l}k^{\prime} \\
\left(\mathrm{s}^{-1}\right)\end{array}$ & $\begin{array}{l}k_{\text {wall }^{b}} \\
\left(\mathrm{~s}^{-1}\right)\end{array}$ & $\begin{array}{c}k_{\text {wall }} \\
\left(\mathbf{s}^{-1}\right)\end{array}$ & $\begin{array}{c}k\left(\mathrm{R}+\mathrm{O}_{2}\right) \\
\left(\mathrm{cm}^{-3} \mathrm{~s}^{-1}\right) \\
10^{-12}\end{array}$ \\
\hline
\end{tabular}

\section{$\left(\mathrm{CH}_{3}\right)_{2} \mathrm{CCH}$}

$\begin{array}{lllllllll}223 & 0.60 & 2.60 & 1.78 & 17.7-36.5 & 185-335 & 98.0 \pm 4.5 & 96.9 \pm 5.7 & 5.47 \pm 0.74 \\ 243 & 0.65 & 2.58 & 2.45 & 9.75-24.7 & 79.3-156 & 20.1 \pm 0.5 & 22.9 \pm 2.5 & 5.46 \pm 0.43 \\ 267 & 0.72 & 2.61 & 3.31 & 13.8-49.9 & 104-250 & 32.1 \pm 0.8 & 32.3 \pm 1.2 & 4.70 \pm 0.41 \\ 298 & 0.80 & 2.59 & 1.31 & 9.02-23.4 & 61.8-105 & 16.9 \pm 1.4 & 17.4 \pm 2.5 & 4.30 \pm 0.62 \\ 298 & 0.80 & 2.59 & 1.47 & 9.21-22.4 & 66.0-126 & 24.1 \pm 2.8 & 24.1 \pm 2.5 & 4.68 \pm 0.40 \\ 304^{\mathrm{d}} & 0.80 & 2.54 & 1.92 & 24.4-96.0 & 204-451 & 110 \pm 8.2 & 111 \pm 4.2 & 3.36 \pm 0.31 \\ 304^{\mathrm{d}} & 0.50 & 1.59 & 1.14 & 19.1-96.7 & 178-476 & 123 \pm 6.4 & 124 \pm 8.8 & 3.72 \pm 0.41 \\ 304^{\mathrm{d}} & 1.60 & 5.08 & 1.50 & 24.7-99.0 & 180-447 & 105 \pm 9.7 & 102 \pm 3.5 & 3.45 \pm 0.27\end{array}$




$\begin{array}{lllllllll}344^{\mathrm{d}} & 0.95 & 2.67 & 3.51 & 24.7-101 & 192-468 & 109 \pm 5.2 & 109 \pm 4.8 & 3.61 \pm 0.37 \\ 384^{\mathrm{d}} & 1.00 & 2.52 & 3.43 & 24.6-108 & 201-467 & 91.5 \pm 4.1 & 92.4 \pm 5.8 & 3.47 \pm 0.44 \\ 438^{\mathrm{d}} & 1.14 & 2.51 & 1.82 & 23.4-110 & 208-512 & 116 \pm 4.1 & 121 \pm 4.9 & 3.46 \pm 0.37 \\ 492^{\mathrm{d}} & 1.33 & 2.61 & 2.39 & 23.1-88.3 & 208-447 & 104 \pm 3.8 & 106 \pm 4.0 & 4.08 \pm 0.32 \\ 566^{\mathrm{d}} & 1.48 & 2.53 & 3.01 & 39.9-95.8 & 191-472 & 117 \pm 4.4 & 117 \pm 5.4 & 3.83 \pm 0.36\end{array}$

\section{$\left(\mathrm{CH}_{3}\right)_{2} \mathrm{CCCH}_{3}$}

$\begin{array}{lllllllll}266 & 0.71 & 2.58 & 3.81 & 10.4-34.7 & 246-456 & 144 \pm 5.4 & 145 \pm 4.9 & 9.32 \pm 0.95 \\ 298 & 0.80 & 2.59 & 1.61 & 5.79-18.4 & 98.1-193 & 41.7 \pm 2.0 & 41.8 \pm 2.8 & 8.71 \pm 1.10 \\ 298 & 1.60 & 5.19 & 1.55 & 9.41-19.2 & 136-216 & 39.2 \pm 3.1 & 41.6 \pm 6.0 & 9.01 \pm 0.92 \\ 336 & 0.91 & 2.62 & 2.78 & 7.55-31.8 & 77.2-270 & 15.3 \pm 0.5 & 15.4 \pm 0.6 & 8.10 \pm 0.58 \\ 363 & 0.97 & 2.79 & 1.28 & 8.01-27.1 & 102-220 & 31.5 \pm 0.8 & 32.0 \pm 1.8 & 7.51 \pm 0.78 \\ 369^{\mathrm{e}} & 0.40 & 1.05 & 3.66 & 20.5-62.6 & 272-614 & 134 \pm 7.8 & 121 \pm 8.1 & 7.13 \pm 1.14 \\ 369^{\mathrm{e}} & 0.60 & 1.57 & 2.71 & 16.4-52.0 & 243-493 & 125 \pm 3.8 & 122 \pm 7.3 & 7.12 \pm 0.60 \\ 369^{\mathrm{e}} & 1.20 & 3.14 & 1.30 & 16.5-65.5 & 251-593 & 115 \pm 4.4 & 116 \pm 3.3 & 7.38 \pm 0.61 \\ 369^{\mathrm{e}} & 2.01 & 5.26 & 1.70 & 27.1-76.5 & 314-680 & 126 \pm 3.1 & 119 \pm 8.2 & 7.11 \pm 0.70 \\ 407^{\mathrm{e}} & 1.02 & 2.42 & 1.09 & 16.6-74.1 & 211-606 & 104 \pm 4.0 & 103 \pm 3.2 & 6.75 \pm 0.56 \\ 418^{\mathrm{e}} & 1.82 & 4.21 & 3.17 & 22.6-78.0 & 283-669 & 121 \pm 3.2 & 115 \pm 3.6 & 6.73 \pm 0.82 \\ 441^{\mathrm{e}} & 1.50 & 3.29 & 3.01 & 14.8-44.8 & 168-367 & 78.8 \pm 2.5 & 78.3 \pm 3.3 & 6.63 \pm 0.62 \\ 485^{\mathrm{e}} & 1.58 & 3.15 & 2.57 & 21.5-56.4 & 254-493 & 110 \pm 3.6 & 108 \pm 4.4 & 6.31 \pm 0.68 \\ 515^{\mathrm{e}} & 1.67 & 3.13 & 3.24 & 16.5-50.6 & 186-395 & 82.7 \pm 2.4 & 83.9 \pm 4.7 & 6.02 \pm 0.55 \\ 554^{\mathrm{e}} & 1.87 & 3.26 & 1.21 & 10.4-51.4 & 163-388 & 94.7 \pm 3.7 & 96.4 \pm 3.9 & 5.72 \pm 0.58 \\ 557^{\mathrm{e}} & 1.94 & 3.36 & 3.66 & 11.7-55.0 & 156-397 & 88.1 \pm 3.3 & 89.2 \pm 2.6 & 5.53 \pm 0.36 \\ 601^{\mathrm{e}} & 2.01 & 3.23 & 2.81 & 23.6-84.6 & 263-591 & 137 \pm 4.9 & 137 \pm 2.4 & 5.29 \pm 0.39\end{array}$

${ }^{\text {a }}$ Chlorine lamp with a $\mathrm{BaF}_{2}$ window was used for detection, stainless steel with halocarbon wax coated reactor with inner diameter $(\mathrm{id})=1.7 \mathrm{~cm}$, unless otherwise stated, $\operatorname{KrF}$ laser $(248 \mathrm{~nm})$ was used for. ${ }^{\mathrm{b}}$ Average of measured wall rates. ${ }^{\mathrm{c}}$ Wall rate determined from the linear fit $y$-axis intercept. ${ }^{\mathrm{d}}$ Quartz reactor with id $=1.7 \mathrm{~cm}$ with polydimethylsiloxane (PDMS) coating. ${ }^{\mathrm{e}}$ Quartz reactor with id $=1.7 \mathrm{~cm}$ with boric acid coating

As shown in Table 1, the bimolecular rate coefficients of reactions (1) and (2) have been measured over the temperature range $223-600 \mathrm{~K}$ and the pressure range $0.4-2$ Torr. In each case the upper end of the employed temperature range was restricted by thermal stability of the photolytic precursor used for producing the radical of interest. Arrhenius plots of reactions (1) and (2) are shown in figure 2. The observed bimolecular rate coefficient of reaction (1) shows a typical negative temperature dependence for the temperature range of 223 - $384 \mathrm{~K}$. However, above about $384 \mathrm{~K}$, the bimolecular rate coefficients appear to become independent of temperature (i.e. $384<T$ ). For reaction (2), the observed bimolecular rate coefficients show a negative temperature dependence throughout the employed temperature range of $266-600 \mathrm{~K}$. By fitting the Arrhenius expression $k=A \times \exp \left(\frac{-E_{a}}{R T}\right)$ 
to the negative temperature dependence portion of the bimolecular rate coefficients of reactions

and (2), the following rate expressions were obtained: $k_{1}=(1.50 \pm 0.4) \times 10^{-12} \exp (2.45 \pm 0.53 \mathrm{~kJ}$ $\left.\mathrm{mol}^{-1} / R T\right) \mathrm{cm}^{3} \mathrm{~s}^{-1}(T=223-384 \mathrm{~K}), k_{2}=(3.48 \pm 0.1) \times 10^{-12} \exp \left(2.27 \pm 0.09 \mathrm{~kJ} \mathrm{~mol}^{-1} / R T\right) \mathrm{cm}^{3} \mathrm{~s}^{-}$ ${ }^{1}(T=266-601 \mathrm{~K})$, where $A$ is the pre-exponential factor, $E_{\mathrm{a}}$ is the activation energy, and $R$ is the gas constant. It can be seen that the obtained negative activation energies are the same within experimental uncertainties. Difference in bimolecular rate coefficients of reactions (1) and (2) is thus related to pre-exponential factor $A$ and on the entropy of activation, suggesting that entropy of activation is slightly more negative for reaction (1) than for reaction (2).

Goldsmith et al. ${ }^{8}$ and Chen et al. ${ }^{9}$ have observed in their theoretical kinetics calculations of $\mathrm{C}_{2} \mathrm{H}_{3}+$ $\mathrm{O}_{2}{ }^{8}$, trans $-\mathrm{CH}_{3} \mathrm{CHCH}+\mathrm{O}_{2}{ }^{9}$, and $\mathrm{CH}_{3} \mathrm{CCH}_{2}+\mathrm{O}_{2}{ }^{9}$ reactions that capture rate is adequate method to model the rate of vinyl-type radical disappearance in these reactions over wide range of temperatures, meaning that dissociation of any intermediate back to products is consequently expected to be negligible. This important observation means that the rate of disappearance of vinyl-type radical in reaction with $\mathrm{O}_{2}$ is at the high-pressure-limit $\left(k_{\infty}\right)$ already at low-pressures, for example in conditions of the current work. Consequently, current results can be used to model combustion kinetics at highpressures. Not surprisingly, bimolecular rate coefficients of reactions (1) and (2) measured in this work were independent of pressure under the employed experimental conditions. Calculations of Goldsmith et al. ${ }^{8}$ and Chen et al. ${ }^{9}$, which agree well with our previous experiments, ${ }^{20,21}$ show that capture rate coefficients of vinyl-type radical reactions with $\mathrm{O}_{2}$ show clear negative temperature dependency below roughly $500 \mathrm{~K}$ until at higher temperatures weak positive dependency is anticipated. These results are in agreement with the current observations; it might be that change from negative to weak positive temperature dependency of reaction (2) occurs at higher temperature we can reach experimentally. 


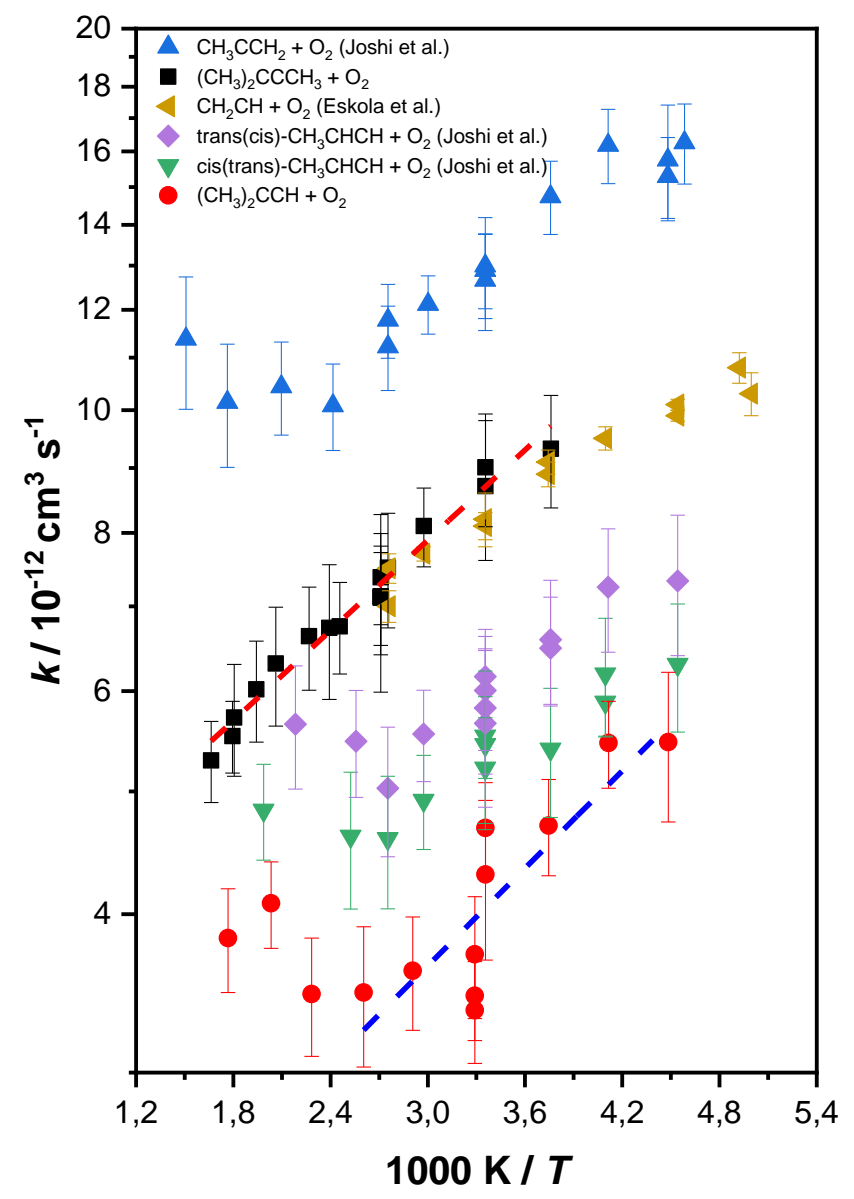

Figure 2. Arrhenius plots of $\left(\mathrm{CH}_{3}\right)_{2} \mathrm{CCH}+\mathrm{O}_{2}$ and $\left(\mathrm{CH}_{3}\right)_{2} \mathrm{CCCH}_{3}+\mathrm{O}_{2}$ reactions, along with Arrhenius plots of previously measured cis/trans- $\mathrm{CH}_{3} \mathrm{CHCH},{ }^{21} \mathrm{CH}_{3} \mathrm{CCH}_{2},{ }^{21}$ and $\mathrm{CH}_{2} \mathrm{CH}^{20}$ radical reactions with molecular oxygen. The blue and red dashed lines represent the Arrhenius fits for $\left(\mathrm{CH}_{3}\right)_{2} \mathrm{CCH}+\mathrm{O}_{2}$ and $\left(\mathrm{CH}_{3}\right)_{2} \mathrm{CCCH}_{3}+\mathrm{O}_{2}$ reactions, respectively.

In figure 2 the current bimolecular rate coefficient of reactions (1) and (2) are compared with the previous results of vinyl-type radical reactions with $\mathrm{O}_{2}$ : $\mathrm{CH}_{2} \mathrm{CH},{ }^{20} \mathrm{CH}_{3} \mathrm{CCH}_{2},{ }^{21}$ and cis/trans$\mathrm{CH}_{3} \mathrm{CHCH}^{21}{ }^{21}$ can be seen from Figure 2 that substituting both the $\beta$-hydrogens with methyl groups in $\mathrm{CH}_{2} \mathrm{CH}$ radical (i.e. producing $\left(\mathrm{CH}_{3}\right)_{2} \mathrm{CCH}$ radical) results in about $\sim 50 \%$ reduction in the bimolecular rate coefficient. Substituting only one $\beta$-hydrogen of $\mathrm{CH}_{2} \mathrm{CH}$ radical with a methyl group produces either a cis- or trans-methylvinyl radical, of which the trans-isomer is slightly more reactive with $\mathrm{O}_{2}$ than the cis-isomer, ${ }^{9}$ but both are about $30 \%$ less reactive than the $\mathrm{CH}_{2} \mathrm{CH}$ radical. Substituting all three hydrogens of $\mathrm{CH}_{2} \mathrm{CH}$ radical with methyl groups results in $\left(\mathrm{CH}_{3}\right)_{2} \mathrm{CCCH}_{3}$ 
radical that shows almost indistinguishable oxidation kinetics compared to $\mathrm{CH}_{2} \mathrm{CH}+\mathrm{O}_{2}$ reaction. This is in agreement with the previous measurements that substituting the $\alpha$-hydrogen of $\mathrm{CH}_{2} \mathrm{CH}$ radical with a methyl group (i.e. producing $\mathrm{CH}_{2} \mathrm{CCH}_{3}$ radical) increases oxidation kinetics about $50 \%$. It would seem that substituting the $\alpha$-hydrogen of $\mathrm{CH}_{2} \mathrm{CH}$ radical with a methyl group compensates for the rate decreasing effect of substituting both the $\beta$-hydrogens atoms with methyl groups.

\section{Conclusion}

The bimolecular rate coefficients of reactions $\left(\mathrm{CH}_{3}\right)_{2} \mathrm{CCH}+\mathrm{O}_{2}$ and $\left(\mathrm{CH}_{3}\right)_{2} \mathrm{CCCH}_{3}+\mathrm{O}_{2}$ have been measured over the temperature and pressure ranges of $223-600 \mathrm{~K}$ and $0.4-2$ Torr. The kinetics of both reactions were observed to be independent of total pressure and are expected to be at the highpressure-limit already under the current experimental conditions. For reaction $\left(\mathrm{CH}_{3}\right)_{2} \mathrm{CCH}+\mathrm{O}_{2}$, the observed rate coefficient shows negative temperature dependence over the temperature range (223-

$384 \mathrm{~K})$ and seems to become temperature independent at higher temperatures $(T>384 \mathrm{~K})$. For $\left(\mathrm{CH}_{3}\right)_{2} \mathrm{CCCH}_{3}+\mathrm{O}_{2}$ reaction, the measured bimolecular rate coefficient shows negative temperature dependence throughout the experimental temperature range $(223-600 \mathrm{~K})$. The products observed for $\left(\mathrm{CH}_{3}\right)_{2} \mathrm{CCH}+\mathrm{O}_{2}$ and $\left(\mathrm{CH}_{3}\right)_{2} \mathrm{CCCH}_{3}+\mathrm{O}_{2}$ reactions suggest that the reaction mechanism is analogous to the $\mathrm{CH}_{2} \mathrm{CH}+\mathrm{O}_{2}$ reaction. Substituting the both $\beta$-hydrogens of $\mathrm{CH}_{2} \mathrm{CH}$ radical with methyl groups decreases its reactivity with $\mathrm{O}_{2}$ by about $\sim 50 \%$. Methyl substitution of all $\mathrm{CH}_{2} \mathrm{CH}$ radical hydrogens does not seem to have any distinguishable kinetic effect on reaction with $\mathrm{O}_{2}$.

\section{Acknowledgement}

S.P.J. and A.J.E. acknowledge support from the Academy of Finland, Grant Nos. 294042/319353, 311967, and 288377. T.T.P. acknowledges support from the Doctoral Programme in Chemistry and Molecular Sciences of the University of Helsinki. 


\section{References}

(1) Wisniewski, A.; Wiggers, V. R.; Simionatto, E. L.; Meier, H. F.; Barros, A. A. C.; Madureira, L. A. S. Biofuels from Waste Fish Oil Pyrolysis: Chemical Composition. Fuel 2010, 89, 563-568.

(2) Morganti, K. J.; Foong, T. M.; Brear, M. J.; da Silva, G.; Yang, Y.; Dryer, F. L. The Research and Motor Octane Numbers of Liquefied Petroleum Gas (LPG). Fuel 2013, 108, 797-811.

(3) Knothe, G. "Designer" Biodiesel: Optimizing Fatty Ester Composition to Improve Fuel Properties. Energy Fuels 2008, 22, 1358-1364.

(4) Meneghetti, S. M. P.; Meneghetti, M. R.; Serra, T. M.; Barbosa, D. C.; Wolf, C. R. Biodiesel Production from Vegetable Oil Mixtures: Cottonseed, Soybean, and Castor Oils. Energy Fuels 2007, 21, 3746-3747.

(5) Rissanen, M. P.; Amedro, D.; Eskola, A. J.; Kurten, T.; Timonen, R. S. Kinetic (T = 201-298 K) and Equilibrium $(\mathrm{T}=320-420 \mathrm{~K})$ Measurements of the $\mathrm{C}_{3} \mathrm{H}_{5}+\mathrm{O}_{2} \leftrightarrows \mathrm{C}_{3} \mathrm{H}_{5} \mathrm{O}_{2}$ Reaction. J. Phys. Chem. A 2012, 116, 3969-3978.

(6) Klippenstein, S. J. From Theoretical Reaction Dynamics to Chemical Modeling of Combustion. Proc. Combust. Inst. 2017, 36, 77-111.

(7) Chen, C.-J.; Bozzelli, J. W. Thermochemical Property, Pathway and Kinetic Analysis on the Reactions of Allylic Isobutenyl Radical with $\mathrm{O}_{2}$ : An Elementary Reaction Mechanism for Isobutene Oxidation. J. Phys. Chem. A 2000, 104, 9715-9732.

(8) Goldsmith, C. F.; Harding, L. B.; Georgievskii, Y.; Miller, J. A.; Klippenstein, S. J. Temperature and Pressure-Dependent Rate Coefficients for the Reaction of Vinyl Radical with Molecular Oxygen. J. Phys. Chem. A 2015, 119, 7766-7779.

(9) Chen, X.; Goldsmith, C. F. A Theoretical and Computational Analysis of the Methyl-Vinyl $+\mathrm{O}_{2}$ Reaction and Its Effects on Propene Combustion. J. Phys. Chem. A 2017, 121, 9173-9184.

(10) Burke, S. M.; Metcalfe, W.; Herbinet, O.; Battin-Leclerc, F.; Haas, F. M.; Santner, J.; Dryer, F. L.; Curran, H. J. An experimental and Modeling Study of Propene Oxidation. Part 1: Speciation Measurements in Jet-Stirred and Flow Reactors. Combust. Flame 2014, 161, 2765-2784.

(11) Zhou, C. W.; Li, Y.; O'Connor, E.; Somers, K. P.; Thion, S.; Keesee, C.; Mathieu, O.; Petersen, E. L.; DeVerter, T. A.; Oehlschlaeger. M. A.; et al. A Comprehensive Experimental and Modeling Study of Isobutene Oxidation. Combust. Flame 2016, 167, 353-379.

(12) Westbrook, C. K.; Pitz, W. J.; Mehl, M.; Glaude, P. A.; Herbinet, O.; Bax, S.; Battin-Leclerc, F.; Mathieu, O.; Petersen, E. L.; Bugler, J.; et al. Experimental and Kinetic Modeling Study of 2Methyl-2-Butene: Allylic Hydrocarbon Kinetics. J. Phys. Chem. A 2015, 119, 7462-7480.

(13) Yang, R.; Yu, L.; Jin, X.; Zhou, M.; Carpenter, B. K. Reaction of Vinyl Radical With Oxygen: A Matrix Isolation Infrared Spectroscopic and Theoretical Study. J. Chem. Phys. 2005, 122, 014511. (14) Westmoreland, P. R. Thermochemistry and Kinetics of $\mathrm{C}_{2} \mathrm{H}_{3}+\mathrm{O}_{2}$ Reactions. Combust. Sci. Technol. 1992, 82, 151-168.

(15) Wang, H.; Wang, B.; He, Y.; Kong, F. The Gaseous Reaction of Vinyl Radical With Oxygen. J. Chem. Phys. 2001, 115, 1742-1746.

(16) Slagle, I. R.; Park, J. Y.; Heaven, M. C.; Gutman, D. Kinetics of Polyatomic Free Radicals Produced by Laser Photolysis. 3. Reaction of Vinyl Radicals With Molecular Oxygen. J. Am. Chem. Soc. 1984, 106, 4356-4361.

(17) Park, J.-Y.; Heaven, M. C.; Gutman, D. Kinetics and Mechanism of the Reaction of Vinyl Radicals With Molecular Oxygen. Chem. Phys. Lett. 1984, 104, 469-474.

(18) Mebel, A. M.; Kislov, V. V. The $\mathrm{C}_{2} \mathrm{H}_{3}+\mathrm{O}_{2}$ Reaction Revisited: Is Multireference Treatment of the Wave Function Really Critical? J. Phys. Chem. A 2005, 109, 6993-6997.

(19) Feng, W.; Wang, B. Reaction of Vinyl Radical With $\mathrm{O}_{2}$ Studied by Time-Resolved Infrared Emission Spectroscopy. Chem. Phys. Lett. 2002, 356, 505-510. 
(20) Eskola, A. J.; Timonen, R. S. Kinetics of the Reactions of Vinyl Radicals With Molecular Oxygen and Chlorine at Temperatures 200-362 K. Phys. Chem. Chem. Phys. 2003, 5, 2557-2561.

(21) Joshi, S. P.; Pekkanen, T. T.; Timonen, R. S.; Lendvay, G.; Eskola, A. J.; Kinetics of the MethylVinyl Radical $+\mathrm{O}_{2}$ Reactions Associated with Propene Oxidation. J. Phys. Chem. A 2019, 123, 9991006.

(22) Niiranen, J. T.; Gutman, D.; Krasnoperov, L. N. Kinetics and Thermochemistry of the $\mathrm{CH}_{3} \mathrm{CO}$ Radical: Study of the $\mathrm{CH}_{3} \mathrm{CO}+\mathrm{HBr} \rightarrow \mathrm{CH}_{3} \mathrm{CHO}+\mathrm{Br}$ Reaction. J. Phys. Chem. 1992, 96, 58815886.

(23) Krasnoperov, L. N.; Niiranen, J. T.; Gutman, D.; Melius, C. F.; Allendorf, M. D. Kinetics and Thermochemistry of $\mathrm{Si}\left(\mathrm{CH}_{3}\right)_{3}+$ NO Reaction: Direct Determination of a Si-N Bond Energy. J. Phys. Chem. 1995, 99, 14347-14358.

(24) Bencsura, A.; Knyazev, V. D.; Slagle, I. R.; Gutman, D.; Tsang, W. Weak Collision Effects in the Reaction $\mathrm{CH}_{3} \mathrm{CO} \rightarrow \mathrm{CH}_{3}+\mathrm{CO}$. Ber. Bunsen-Ges. Phys. Chem. Chem. Phys. 1992, 96, 13381347.

(25) Knyazev, V. D.; Slagle, I. R. Kinetics of the Reaction of Vinyl Radical With Molecular Oxygen. J. Phys. Chem. 1995, 99, 2247-2249.

(26) Mebel, A. M.; Diau, E. W. G.; Lin, M. C.; Morokuma, K. Ab Initio and RRKM Calculations for Multichannel Rate Constants of the $\mathrm{C}_{2} \mathrm{H}_{3}+\mathrm{O}_{2}$ Reaction. J. Am. Chem. Soc. 1996, 118, 9759-9771.

\section{TOC Graphic}

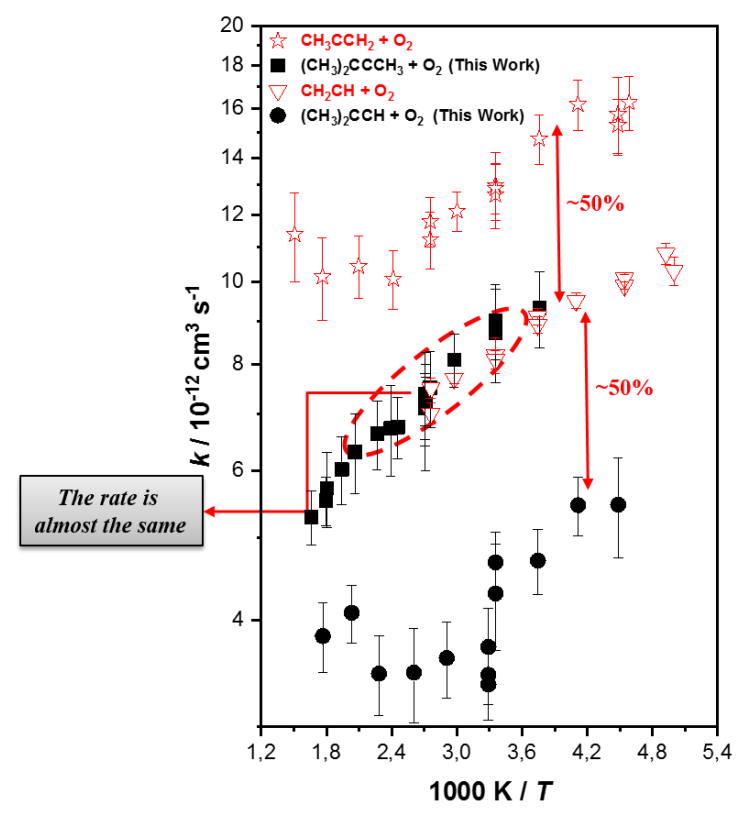

